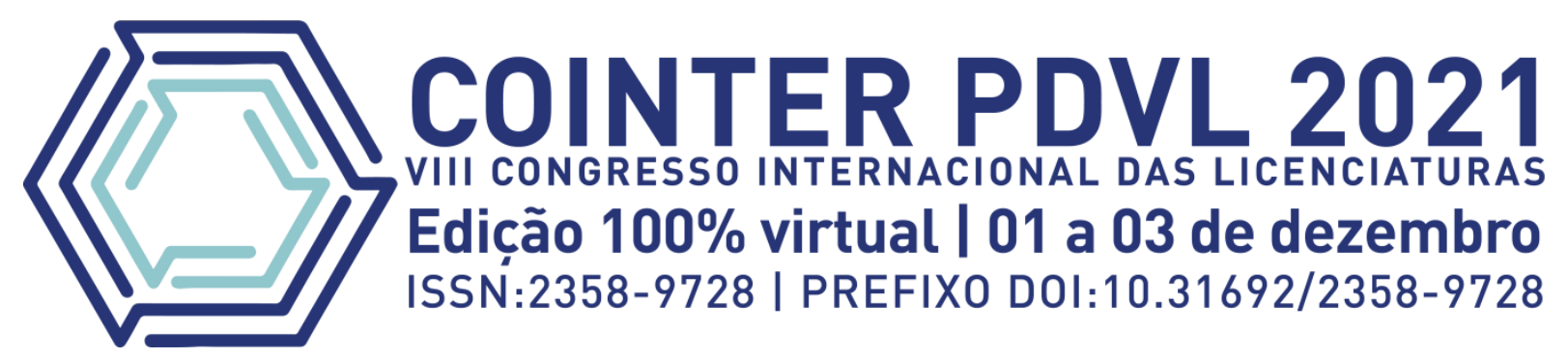

\title{
CICLO DE PALESTRAS: CONTEXTUALIZANDO A QUÍMICA PARA OS DISCENTES DO CURSO DE LICENCIATURA.
}

\section{CICLO DE CONFERENCIAS: CONTEXTUALIZACIÓN DE LA QUÍMICA PARA ESTUDIANTES DE PREGADO.}

\section{CYCLE OF LECTURES: CONTEXTUALIZING CHEMISTRY FOR UNDERGRADUATE STUDENTS.}

\author{
Apresentação: Comunicação Oral \\ Júlia Maria Soares Ferraz ${ }^{1}$; Luana Kelly de Lima²; Bruno Galdino Lopes ${ }^{3}$; Rhayane de Oliveira Santos ${ }^{4}$; \\ Alessandra Marcone Tavares Alves de Figueirêdo ${ }^{5}$
}

\section{RESUMO}

DOI: https://doi.org/10.31692/2526-7701.VIIICOINTERPDVL.0215

A Química é uma ciência que engloba a compreensão de diversos fenômenos e transformações ocorridas no universo. Sendo assim, a utilização de temáticas diversificadas concomitante ao ensino dessa ciência, torna-se imprescindível na formação dos discentes. Nessa perspectiva, o grupo de discentes e da tutora pertencente ao Programa de Educação Tutorial- PET Química, do Instituto Federal da Paraíba - IFPB, oferece uma atividade de ensino denominada "Ciclo de Palestras", que tem o objetivo de contribuir de forma significativa na formação acadêmica dos graduandos do curso de licenciatura em Química, abordando temas presentes no cotidiano, mas que não estão presentes na matriz curricular do curso mencionado. As metodologias utilizadas para a execução desse trabalho foram de cunho qualitativo e participante. Para o desenvolvimento da atividade foi disponibilizado um Instrumento de Sondagem Avaliativo (ISA), com o intuito de obter informações acerca dos conhecimentos prévios dos participantes sobre as temáticas que iriam ser abordadas. Em seguida, foram ministradas pelos integrantes do grupo supracitado, duas palestras, intituladas como, "O estudo da Alquimia na cultura POP" e "Revelando a Química: o estudo das ciências nas fotografias". Subsequentemente, foi entregue um instrumento Final Avaliativo (IFA), objetivando coletar os dados após a intervenção das palestras e, dessa forma, analisar o progresso obtido pelos estudantes. Com os resultados alcançados, oriundos dos IFA, é notório a importância que práxis como essa tem na formação de futuros professores, pois desperta um senso crítico em relação ao ensino de Química vinculado ao cotidiano, estimulando o uso de temáticas que vão além da matriz curricular. A utilização de metodologias diversificadas, como o "Ciclo de Palestras" é de suma importância para o processo de ensino e aprendizagem do ensino de Química, corroborando com a troca de saberes e desenvolvendo competências e habilidades fundamentais para a prática pedagógica desses licenciandos.

Palavras-Chave: Alquimia, Fotografia, Ensino de Química, Palestras.

\footnotetext{
${ }^{1}$ Graduanda em Licenciatura em Química, IFPB Campus João Pessoa, julia.ferraz@academico.ifpb.edu.br

2 Graduanda em Licenciatura em Química, IFPB Campus João Pessoa, lima.luana@academico.ifpb.edu.br

${ }^{3}$ Graduando em Licenciatura em Química, IFPB Campus João Pessoa, bruno.galdino@academico.ifpb.edu.br

${ }^{4}$ Graduanda em Licenciatura em Química, IFPB Campus João Pessoa, rhayane.santos@academico.ifpb.edu.br

${ }^{5}$ Doutora em Química, IFPB Campus João Pessoa, alessandratavaresfigueiredo@ifpb.edu.br
} 


\section{CICLO DE PALESTRAS}

\section{RESUMEN}

La química es una ciencia que abarca la comprensión de diversos fenómenos y transformaciones que tienen lugar en el universo. Siendo además, el uso de temáticas diversificadas concomitantes a la enseñanza de las ciencias, se torna fundamental para la formación de dos estudiantes. En esta perspectiva, el grupo de estudiantes y el tutor perteneciente al Programa de Educación Tutorial-PET Química, del Instituto Federal de Paraíba - IFPB, ofrece una actividad especial denominada "Ciclo de Lecturas", que tiene como objetivo contribuir significativamente a la formación académica de dos egresados de la Licenciatura en Química. Abordando temas no cotidianos, en lugar de no estar presentes en el plan de estudios del mencionado curso. Las metodologías utilizadas para implementar el curso trabajo de cada cualitativo y participante. Para el desarrollo de las actividades se puso a disposición un Instrumento de Encuesta de Evaluación (ISA) como forma de obtener información sobre dos conocimientos previos de dos participantes sobre los temas que se abordarán. A continuación, los integrantes de ese grupo impartieron dos conferencias, titulada como, "El estudio de la Alquimia en la cultura POP" y "Química Reveladora: el estudio de la ciencia en fotografías". Posteriormente, se entregó un instrumento de Encuesta de Evaluación Final (IFA), con el objetivo de recoger datos tras la intervención de las conferencias y, de esta forma, analizar los avances realizados por los alumnos. Con los resultados obtenidos a partir de los IFA, queda patente la importancia que tiene una práctica como esta en la formación de los futuros docentes, ya que despierta un sentido crítico en relación a la enseñanza de la Química vinculada a la vida cotidiana, fomentando el uso de temas que van más allá del plan de estudios de la matriz. El uso de metodologías diversificadas, como el "Ciclo de conferencias" es de suma importancia para el proceso de enseñanza y aprendizaje de la enseñanza de la Química, contribuyendo al intercambio de conocimientos y desarrollando habilidades y destrezas fundamentales para la práctica pedagógica de estos estudiantes de pregrado.

Palabras Clave: Alquimia, Fotografía, Didáctica de la Química, Conferencias.

\section{ABSTRACT}

Chemistry is a science that encompasses the understanding of various phenomena and transformations occurring in the universe. Therefore, the use of diversified themes concomitant with the teaching of this science becomes essential in the training of students. In this perspective, the group of students and tutor belonging to the Tutorial Education Program - PET Chemistry, of the Federal Institute of Paraíba - IFPB, offers a teaching activity called "Cycle of Lectures", which aims to significantly contribute to the academic training of undergraduates in the Chemistry degree course, addressing issues that are present in everyday life, but that are not present in the curriculum of the mentioned course. The methodologies used to carry out this work were qualitative and participatory. For the development of the activity, an Evaluation Survey Instrument (ISA) was made available, in order to obtain information about the prior knowledge of the participants on the themes that would be addressed. Then, two lectures were given by the members of the aforementioned group, entitled "The study of Alchemy in the POP culture" and "Revealing Chemistry: the study of science in photographs". Subsequently, a Final Evaluation Survey (IFA) instrument was delivered, aiming to collect data after the intervention of the lectures and, in this way, analyze the progress made by the students. With the results achieved from the IFA, the importance that practice like this has in the training of future teachers is clear, as it awakens a critical sense in relation to the teaching of Chemistry linked to daily life, encouraging the use of themes that go beyond the matrix curriculum. The use of diversified methodologies, such as the "Cycle of Lectures" is of paramount importance for the teaching and learning process of teaching Chemistry, contributing to the exchange of knowledge and developing fundamental skills and abilities for the pedagogical practice of these undergraduates.

Keywords: Alchemy, Photography, Chemistry Teaching, Lectures.

\section{INTRODUÇÃO}

O ensino de Química é considerado, pela maioria dos discentes, como difícil, e essa dificuldade está relacionada a diversos fatores, entre eles, a forma na qual os conteúdos estão 
sendo abordados, frequentemente, sem contextualização. Entretanto, a contextualização é uma maneira de qualificar e aprimorar a aprendizagem, de forma que os discentes relacionam os saberes da sociedade com os conteúdos científicos, tornando-se um mecanismo facilitador, pois, quando o estudante consegue associar um determinado conceito teórico com a prática cotidiana, o entendimento se torna real e verdadeiro (FINGER; BEDIN, 2019).

Nesse sentido, se faz necessário a busca pela diversificação dos conteúdos no ensino de Química nos cursos de formação docente, de modo a possibilitar a abordagem de temas de interesse da sociedade. Para tanto, a proposta deste trabalho buscou sanar essa necessidade, se justificando no objetivo de contribuir para a formação acadêmica dos discentes do curso de Licenciatura em Química do Instituto Federal de Educação, Ciência e Tecnologia da Paraíba IFPB, Campus João Pessoa, Brasil, por meio de uma atividade de ensino denominada "Ciclo de Palestras" a qual faz uso de temas geradores que muitas vezes estão presentes no dia a dia dos educandos e educador (COSTA; PINHEIRO, 2013).

Assim sendo, a primeira palestra intitulada como, "O estudo da Alquimia na cultura $P O P$ " teve a finalidade de destacar itens da cultura popular - POP, como uma alternativa de ensino devido sua presença no cotidiano, tornando-se útil para contextualização. Dessa forma, a palestra relacionou as práticas alquímicas presentes em filmes e animes com os conceitos teóricos.

Enquanto que, a segunda palestra, "Revelando a Química: o estudo das ciências nas fotografias”, teve o propósito de contextualizar a Química com o processo de produção das fotografias, considerando que esta temática possibilita discussões pertinentes com os conteúdos que são estudados no decorrer do curso de Licenciatura em Química, por exemplo, como as reações de oxirredução presentes no funcionamento das câmeras analógicas.

\section{FUNDAMENTAÇÃO TEÓRICA}

A contextualização no ensino, segundo os autores Gomes e Costa (2017), surgiu a partir da reformulação que foi proposta pela Lei de Diretrizes e Bases da Educação Nacional (LDB - no 9.394/1996), e que depois disso vem sendo respaldada pelos Parâmetros Curriculares Nacionais (PCNs), que descrevem como a educação deve favorecer a compreensão dos temas para o uso do cotidiano. Desde então, a contextualização está presente na maioria dos discursos de professores e pesquisadores, como uma característica importante que deve estar presente no meio educacional.

Nesse sentido, se questiona muito a maneira sistematizada que vem sendo conduzida a disciplina de Química atualmente, tanto no ensino básico, como nos cursos de formação 


\section{CICLO DE PALESTRAS}

docente (GOMES; COSTA, 2017). Por isso, muitos educadores já buscam inovações para atender essa demanda, se norteando a partir das condições estimulantes a qual essa característica traz para os estudantes e futuros docentes, além de contribuir para a melhoria da qualidade do ensino e aprendizagem (SANTOS; AMARAL, 2020).

Assim, o ensino de Química para os futuros professores deve contar com a prática da contextualização, pois deve facilitar a leitura do mundo, o que muitas das vezes não acontece, apesar de saber fórmulas e memorizar reações. Então, para ter essa proficuidade, Santos e colaboradores explicam que "[...] é preciso um ensino que desenvolva no aluno a capacidade de "ver" a Química que ocorre nas múltiplas situações reais e que se apresentam modificadas a cada momento"(2020, p. 3).

Nessa perspectiva de contextualização do ensino, surge a proposta dos Temas Geradores, que é uma metodologia pedagógica muitas vezes utilizada quando pressupõe um estudo da realidade e de problemas encontrados no cotidiano dos educandos (FREIRE, 1987). Além disso, tal método defende a dialogicidade como essência da educação, pois segundo o difusor dessa metodologia, é de onde nascem os temas geradores.

Assim, Freire (1982), ainda orienta que uma temática, quando trabalhada, precisa estar associada à vida dos discentes, isto é, precisa que estes possuam conhecimentos prévios sobre o assunto, e o educador com base na sua vivência junto aos educandos deve saber pelo menos qual o contexto social que seu alunado está inserido. Porquanto, para esse tipo de prática educacional é preciso haver problematização de questões existenciais para que os temas geradores sejam significativos.

Por consequência, no ensino de Química, professores e pesquisadores intensificam seus estudos para aperfeiçoar esses novos métodos que viabilizem o ensino e aprendizagem dos conteúdos químicos, embora, ainda seja utilizado por muitos o ensino expositivo tradicionalista (CAVALCANTE; TEIXEIRA; MARCELO, 2019).

Dessa maneira, se faz urgente e necessário utilizar desses métodos no intuito de aperfeiçoar o ensino de Química e complementar a formação docente, não só visando a melhoria da qualidade do ensino do estudante em formação, mas também que sirva para o licenciando, quando formado, como exemplo em sua carreira profissional. Haja vista, que essa pedagogia “[...] favorece as relações entre situações individuais, históricas e sociais, contribuindo com a discussão, interpretação, compreensão, representação e transformação dessa realidade" (MIRANDA; PAZINATO; BRAIBANTE, 2017, p.75).

Outrossim, além dos tradicionais materiais didáticos utilizados pelos professores, há uma vasta opção de recursos que auxiliam o docente no processo de ensino e aprendizagem, 
como os filmes, séries, softwares, documentários, entre outros. Essa variedade de materiais pode ser utilizada também para oferecer aulas mais dinâmicas e de baixo custo (SANTOS; CRISTINA; CARVALHO, 2020).

Nessa conjuntura, a cultura popular ou cultura POP, torna-se uma alternativa de ensino interessante, abordando conteúdos considerados difíceis na forma de entretenimento, instigando a atenção e o interesse dos discentes. Visto que, a cultura popular aborda tanto a realidade, quanto a ficção, servindo como inspiração e exemplos para o ensino e práticas escolares, devido a sua grande notoriedade entre jovens e crianças (OLIVEIRA, 2021).

De acordo com Oliveira (2021), uma sociedade é formada com uma grande variedade de pessoas e costumes. Quanto maior a sociedade, mais diversificada será, ou seja, existirá nesse meio, diversas formas de se expressar e enxergar o mundo, pois cada indivíduo se identifica com uma forma de arte, e todos eles compartilham algo em comum, formando assim a cultura POP.

Dentro dessa perspectiva, a Alquimia é um conteúdo de suma importância para história da Química, devido às grandes contribuições para essa ciência. Ferreira (2012), sugere que a Química nasceu da Alquimia, ou da decomposição da ideologia alquímica, herdando procedimentos, materiais e algumas técnicas. Portanto, esse conteúdo, atrelado aos produtos da cultura POP, como exemplo das práticas alquímicas nos filmes da saga Harry Potter, podem ser úteis para contextualizar os conceitos químicos, permitindo que os estudantes conheçam as origens dessa ciência, compreendam sua evolução e as contribuições em consequência das descobertas e experimentos antigos.

Não diferente da temática da Alquimia na cultura POP, a fotografia é um tema relevante e interessante para ser usado como forma de contextualização dos conteúdos da disciplina de Química. Uma vez que, “a fotografia é uma forma de comunicação não verbal, de registro de fatos e acontecimentos, muito utilizada na sociedade e de fácil acesso. Por isso, pode ser usada como ferramenta de ensino e divulgação científica” (LIMA; CUNHA, 2020, p. 3, grifo nosso).

Mais adiante, a técnica fotográfica além de estar muito presente no contexto social, teve seu aprimoramento a partir do desenvolvimento da câmera fotográfica, esse instrumento foi resultado de estudos realizados ao longo da história por diversos pesquisadores, que estudaram sobre os fenômenos óticos e as experiências Físicas e Químicas sobre ação da luz em determinados suportes (ROCHA; LEAL; MESSEDER, 2019).

Nesse ensejo, estudar a ciência por trás dessa máquina e da fotografia, é muito útil para a qualificação do licenciando em Química, pois além de tratar de temas estudados nas 


\section{CICLO DE PALESTRAS}

disciplinas do curso, como: oxirredução, espectrometria, complexação, entre outros, ainda envolve toda uma contextualização e incorpora a interdisciplinaridade (MARTINS, et al., 2017).

Portanto, segundo autores como Rocha, Leal e Messeder (2019), os temas que englobam a fotografia podem ser utilizados como instrumentos para a avaliação e complementação de muitos saberes dos graduandos, sobretudo, dos conceitos químicos, além de servir como reforço para que esses estudantes percebam a presença da Química no seu dia a dia.

\section{METODOLOGIA}

Atentando ao atual cenário pandêmico decorrente do novo Coronavírus, o COVID-19, as instituições de ensino, de modo geral, migraram do ambiente de sala de aula presencial para os meios remotos, fazendo constante uso das Tecnologias Digitais de Informação e Comunicação (TDICs). Essa súbita mudança das práticas educacionais, trouxe diversos desafios de adaptação para uma efetiva continuidade no processo de ensino e aprendizagem das escolas (SANTOS; FERREIRA, 2021).

Dentro desse contexto, as atividades de ensino, pesquisa e extensão promovidas pelo Programa de Educação Tutorial - PET Química do IFPB - Campus João Pessoa, vêm sendo produzidas e oferecidas por intermédio de recursos tecnológicos e de forma remota. Sendo assim, a atividade de ensino denominada "Ciclo de Palestras", que costumava ser desenvolvida anualmente de forma presencial pelos bolsistas do grupo PET, adveio por transmissões online no Google Meet.

Assim, o presente trabalho relata as apresentações das palestras intituladas de " $O$ estudo da Alquimia na cultura POP" e "Revelando a Química: o estudo das ciências nas fotografias", que ocorreram nesta respectiva ordem, de modo que ambas tiveram grande foco na explanação e contextualização de conhecimentos químicos pouco debatidos, tanto na Licenciatura, quanto durante o período do Ensino Médio.

Previamente, o planejamento das duas palestras foi desenvolvido mediante revisões bibliográficas relativas às temáticas de: "Alquimia", dentro da perspectiva histórica da ciência e como ela é retratada nas produções da cultura popular, para a primeira apresentação; e "Fotografia", com a finalidade de discutir esse assunto imerso a conceitos químicos, para a segunda. Tais leituras serviram de fundamentação, pois essa modalidade de pesquisa é indispensável para a construção do saber científico (LIMA; MIOTO, 2007).

No entanto, a abordagem que norteou efetivamente todo o processo de busca das 
atividades supracitadas, teve como natureza um método qualitativo, visto que para Mól (2017), esse parâmetro metodológico e científico é essencial, já que por meio dele se entende a educação como um processo interativo, no qual sempre haverá certa mediação na relação entre professores, estudantes e os conceitos específicos da disciplina de Química.

Além disso, a modalidade de investigação empregada foi a participante, pois ela permite a promoção de práticas para a delimitação da pesquisa, escolha de métodos e ferramentas (ANTUNES et al., 2018). Ademais, as abordagens qualitativa e participante foram utilizadas para uma análise mais acentuada concernente ao fato estudado, considerando em todas as hipóteses possíveis a experiência profissional dos pesquisadores e dos pesquisados (RAUPP; BEUREN, 2006).

O público-alvo do "Ciclo de Palestras" se restringiu aos estudantes, de diversos períodos, do curso de Licenciatura em Química do IFPB, Campus João Pessoa. Nas duas palestras participaram 19 (dezenove) licenciandos, além dos integrantes do programa PET Química. As apresentações com discussões tiveram em média uma durabilidade de 50 (cinquenta) minutos, seguidos de mais 10 (dez) minutos dedicados às considerações dos graduandos e dos palestrantes.

O modelo de apresentação dessa atividade seguiu os princípios práticos de aulas expositivas dialogadas relacionadas aos contextos contemporâneos, que como bem apontou Marques (2021), vão além de meras apresentações de teorias, leis e conceitos, promovendo o senso crítico e reflexivo dos estudantes a respeito de seus entendimentos sobre a ciência.

No que tange à execução da atividade de ensino, a dinâmica se deu em três momentos: no primeiro momento foi disponibilizado para os estudantes de Química, um Instrumento de Sondagem Avaliativo (ISA) que era composto por sete questões, sendo seis dessas relativas a informações pessoais dos participantes e, uma a evocação livre de palavras alusivas às temáticas de cada palestra, pois esta técnica amplia os resultados e a compreensão dos estudos cognitivistas e científicos (NEVES et al., 2014).

Em sequência, no segundo momento, foram iniciadas as ministrações das palestras com discussões bem fundamentadas em parceria, tanto com os interlocutores, quanto com os espectadores, nas quais foram explanados diversos tópicos pertinentes aos seus respectivos temas. Ao final, terceiro momento, foi fornecido um último questionário, o Instrumento Final Avaliativo (IFA) que possuía nove perguntas para a primeira palestra, sendo seis no tocante a identificação dos estudantes, uma questão relativa a evocação livre de palavras sobre o assunto proposto, e duas sobre as considerações dos licenciandos concernente à palestra. Para a segunda apresentação foi seguido o mesmo andamento, porém nessa foram três 


\section{CICLO DE PALESTRAS}

questionamentos acerca dos comentários dos participantes.

\section{RESULTADOS E DISCUSSÃO}

Após a efetivação de todos os passos propostos para a realização das apresentações, foi feita a reunião dos resultados oriundos dos Instrumentos Avaliativos e da observação qualitativa durante todo processo de discussão das temáticas expostas no "Ciclo de Palestras". Vale salientar que, para preservação da identidade dos graduandos, nas etapas que necessitam da descrição de cada aluno, o nome deles foi substituído pelos termos "Aluno A", “Aluno B” e, assim, sucessivamente.

A priori, serão demonstrados os resultados da primeira palestra "O estudo da Alquimia na cultura POP" e, posteriormente, os resultados da segunda palestra "Revelando a Química: o estudo das ciências nas fotografias".

No momento inicial da primeira palestra, foi aplicado o Instrumento de Sondagem Avaliativo, utilizando a técnica da evocação livre de palavras. A questão constituinte deste instrumento discorreu em: "Quando você escuta a palavra "Alquimia", o que lhe vem primeiro a mente?". A escolha da palavra-chave utilizada para que os licenciandos realizassem as associações, teve objetivo de auxiliar os pesquisadores a compreender o nível de entendimento que os estudantes obtinham em relação ao termo supramencionado. Assim, por meio deste primeiro instrumento, foi efetuada a tabulação dos dados, conforme exibe o Quadro 01

Quadro 01: Palavras associadas à Alquimia no ISA.

\begin{tabular}{|c|l|}
\hline Pesquisados & \multicolumn{1}{|c|}{ Sobre Alquimia } \\
\hline Aluno A & Magia; Poções; Magos. \\
\hline Aluno B & Poções, Experiências, Magia. \\
\hline Aluno C & Desconheço. \\
\hline Aluno D & Pedra filosofal; Ouro; Imortalidade. \\
\hline Aluno E & Idade Média; Pedra Filosofal; Doença. \\
\hline Aluno F & Idade média; Misticismo; Transformações. \\
\hline Aluno G & Magia; Medicina; Religião. \\
\hline Aluno H & Pioneirismo; Alquimistas; Misturas. \\
\hline & \multicolumn{1}{|c|}{ Fonte: Própria (2021). } \\
\hline & \\
\hline & \\
\hline &
\end{tabular}

provenientes do ISA, podendo ser observado que boa parte destes, estão diretamente relacionados com a deturpada compreensão no que se refere à Alquimia, de modo que apesar de seus diversos legados deixados para a Química e muitas outras áreas da ciência, ainda existem fatores que acabam dispersando sua real definição e resumindo a um trivial acontecimento histórico sem fundamentos relevantes. 
Dentro deste contexto, Nascimento e Simões Neto (2012), discorrem que a má compreensão dos aspectos científico-filosóficos que conceituam a Alquimia, acaba por simplificá-la intensamente às noções como ocultismo ou mera feitiçaria, reforçando que na Alquimia não existem métodos e cientificidade, o que dificulta o ato de formalizar este assunto. Nesse sentido, os dados do ISA alegaram a falta de debates com devido embasamento no conteúdo, limitando-o a um fato fantasioso e omitindo sua colaboração para a ciência contemporânea.

No segundo momento, ocorreu a apresentação propriamente dita da palestra, na qual foram expostas informações fundamentadas sobre a história da Alquimia e suas contribuições para Química, Medicina, Metalúrgica, Física, entre outros ramos da ciência. Concomitantemente a esta explanação, houve constante contextualização com produções culturais conhecidas pelo público-alvo, como o filme Harry Potter e a Pedra Filosofal e o anime Fullmetal Alchemist.

O debate promovido a respeito da validade dessa correlação conteúdo-Cultura POP, apresentou aos estudantes de Licenciatura em Química, um ponto positivo, como por exemplo, o fato de despertar interesse nos alunos de Ensino Médio, se caracterizando como um eficiente método para utilização em sala de aula. Quanto a um ponto negativo, é visto a necessidade de sempre estar alerta ao utilizar este recurso, devido à condição de que geralmente as produções culturais acabam por estereotipar a figura ou as ações dos cientistas e alquimistas.

Esta percepção indica que é totalmente viável a aplicabilidade da contextualização com a "Cultura POP”, pois une os discentes com a disciplina, por sua constante presença na vivência dos mesmos (LOBO, 2019), todavia, é preciso um devido cuidado ao utilizá-la. A Figura 01, ilustra os registros da primeira palestra.

Figura 01: Registro da primeira palestra: "O estudo da Alquimia na cultura POP".

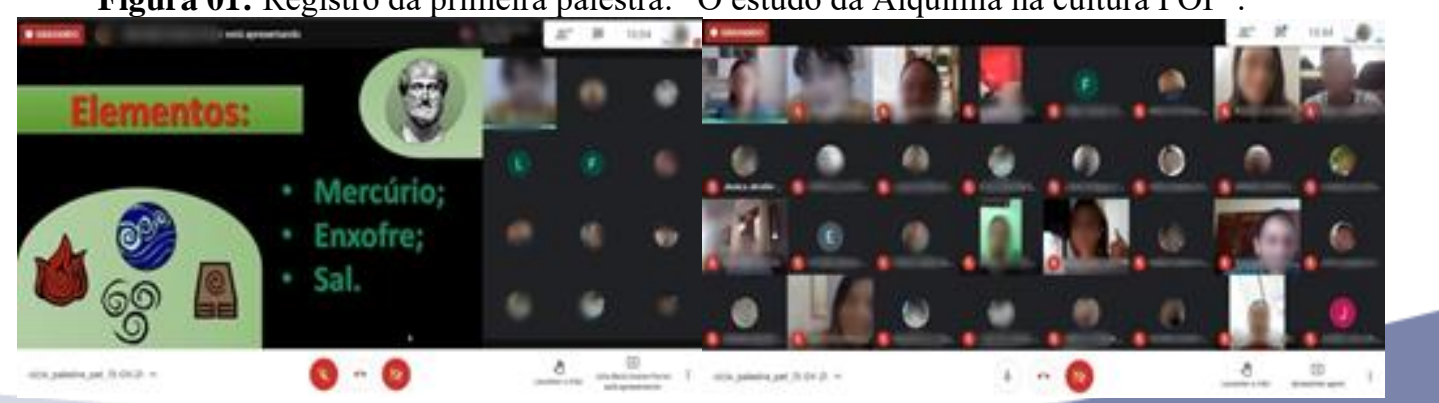

Fonte: Própria (2021).

Durante a apresentação da palestra foi possível constatar diversos fatores meritórios, tais como: a participação efetiva dos alunos durante o momento de discussão do assunto; as considerações apresentadas no que diz respeito à carência da oferta de aplicabilidades e 


\section{CICLO DE PALESTRAS}

conversações relativas ao conteúdo de Alquimia e sua importância como fator histórico para o entendimento de conteúdos subsequentes da disciplina de Química; a condição de mediação entre o conteúdo em pauta e sua representação nos filmes, animes e/ou jogos.

No terceiro momento, aplicou-se o Instrumento Final Avaliativo, o primeiro questionamento elencou: I. "Após sua participação na palestra, responda novamente o que lhe vem à mente ao escutar a palavra "Alquimia". Para isso, cite 3 (três) palavras-chave que rapidamente você associa ao alusivo termo". As respostas dessa questão, também foram obtidas a partir das evocações livres de palavras e estão mostradas no Quadro 02.

Quadro 02: Palavras associadas à Alquimia no IFA.

\begin{tabular}{|c|l|}
\hline Pesquisados & \multicolumn{1}{c|}{ Sobre Alquimia } \\
\hline Aluno A & Introdução à ciência atual; Filosofia; Primeiros experimentos. \\
\hline Aluno B & Filosofia; Ciência; Conhecimento. \\
\hline Aluno C & Transmutações. \\
\hline Aluno D & Pedra filosofal; Metais; Paracelso. \\
\hline Aluno E & Introdução a Química; Idade Média; Transformações. \\
\hline Aluno F & Cientistas; Descobertas; Conhecimentos. \\
\hline Aluno G & Transmutações; Perseguição; Ciência. \\
\hline Aluno H & Evolução; Ciência; Combinação dos elementos. \\
\hline
\end{tabular}

Fonte: Própria (2021).

Diferente dos termos nos ISA que acabavam omitindo a visualização da Alquimia como ciência e suas colaborações, os IFA apresentaram fatores recorrentes sobre a importância do pioneirismo científico desta temática. Deste modo, é preciso desmistificar o termo "Alquimia" por intermédio do aumento de discussões sobre a sua relevância introdutória à Química atual. Melo e Rocha (2017) relatam que, é de imensa eficácia e funcionalidade a interação entre a ciência e seu processo histórico, para a evolução da mesma. Desta maneira, a atividade de ensino relatada se mostrou como uma ação urgente na formação e atuação docente.

Em suma, tais análises narraram as considerações dos discentes para com a palestra, visto que boa parte deles relataram a necessidade da explanação do tema e sua resoluta aplicação no Ensino Médio, assim como no Ensino Superior. Essa avaliação positiva pode ser constatada nos comentários dos alunos no IFA, na questão: II. "O que você achou da palestra intitulada: " O estudo da Alquimia na cultura POP”?", de modo que eles responderam: Aluno A. "O título representa bem a palestra que foi ministrada, visto que, pôde-se perceber a influência e o pioneirismo das primeiras pessoas que praticaram ciência e logo foram denominados alquimistas.”; Aluno B. “Um tema muito importante e necessário que não se vê com frequência, foi ótimo e a palestrante explicou muito bem. Parabéns!”; Aluno C. "Eu nunca tinha estudado sobre essa temática, foi incrível aprender como a alquimia contribuiu 
para a ciência atual”. Dessa forma, o público avaliou positivamente a atividade, expondo a efetividade da discussão.

Em alusão à segunda palestra, como já mencionado, o método de análise dos resultados também foi feito utilizando o Instrumento de Sondagem Avaliativo e o Instrumento Final Avaliativo. No primeiro momento, foi disponibilizado o ISA para os discentes o qual foi constituído pela seguinte pergunta: "Ao ouvir a palavra "Fotografia" o que lhe vem primeiro à mente? Responda a esta pergunta citando 5 (cinco) palavras que você rapidamente associa com o termo referenciado." Em conseguinte, os dados foram tabulados Quadro 03, de maneira que neste primeiro momento, os sujeitos da pesquisa associaram o termo "Fotografia" com assuntos diversos.

\begin{tabular}{|c|l|}
\hline \multicolumn{1}{l}{ Quadro 03 - Palavras associadas à Fotografia no ISA. } \\
\hline Pesquisados & \multicolumn{1}{c|}{ ISA } \\
\hline Aluno A & Momentos; Registro; Flash; Imagens; Câmera. \\
\hline Aluno B & Curiosidade; Acontecimento; História. \\
\hline Aluno C & Registro; Memória; Luz; Revelação; Digital. \\
\hline Aluno D & Memórias; Cores; Papel; Tinta; Perspectiva. \\
\hline Aluno E & Imagem; Arte de registrar; Acontecimentos; Câmera; Exposição. \\
\hline Aluno F & Impressão; Reação química; Sala escura. \\
\hline Aluno G & Câmera; Registro; Imagem; Arte; Momentos. \\
\hline Aluno H & Registro; Imagem; Câmera; Captura momentos. \\
\hline
\end{tabular}
Fonte: Própria (2021).

As expressões apontadas nas associações livres revelam que os estudantes de Química, em quase nenhuma das palavras, relacionaram a temática de imediato com conteúdos componentes das disciplinas. Realizando uma averiguação qualitativa mais aprofundada dos fatores resultantes do ISA, entendeu-se que a ausência da utilização de recursos cotidianos, como a produção das fotografias ou o funcionamento das câmeras, no processo de contextualização de conteúdos químicos, como no exemplo das reações oxirredução, ainda é uma falha no processo de formação docente, que acaba sendo refletido na atuação prática desses professores em sala de aula.

Na literatura, o princípio da contextualização também é apontado como fator que não se desvincula do processo de ensino e aprendizagem ( $\mathrm{PCN}+, 2002)$, neste entendimento, o professor precisa adotar um rico perfil de competências de forma a contribuir para que os alunos consigam despertar habilidades necessárias, que os possibilitem a desenvolver soluções para os problemas propostos nas aulas, os tornando seres mais críticos e reflexivos (ALBUQUERQUE, 2019).

O segundo momento se deu na apresentação da palestra intitulada "Revelando a

Química: o estudo das ciências nas fotografias", pela qual foram feitas numerosas discussões 


\section{CICLO DE PALESTRAS}

relativas à efetividade da vinculação do assunto em pauta com os conceitos científicos. Neste processo, foram debatidos fatores referentes ao procedimento e preparação das fotografias, assim como o funcionamento das câmeras analógicas e digitais. Toda a explicação que norteou as técnicas de fotografias foi contextualizada com os seguintes conteúdos químicos: Reações Químicas; Oxirredução e Espectrometria. A Figura 02, exibe os registros dessa segunda palestra.

Figura 02: Registro da segunda palestra: "Revelando a Quimica: o estudo das ciências nas fotografias".

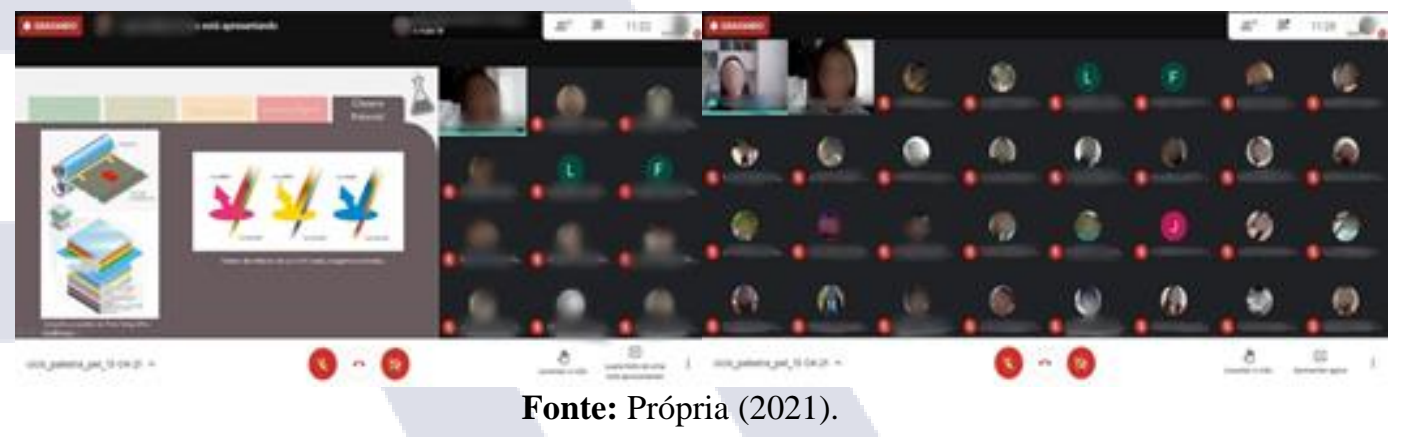

No terceiro e último momento da palestra, foi aplicado o IFA que iniciou com a seguinte pergunta: “Já ouviu falar sobre o tema?”. O Gráfico 01 demonstra a porcentagem dos participantes da pesquisa que afirmaram já ter ouvido sobre a temática, assim como a porcentagem dos que disseram nunca ter tido contato com o assunto.

Gráfico 01: Porcentagem das respostas dos participantes de acordo com o IFA.

\section{Já ouviu falar sobre o tema?}

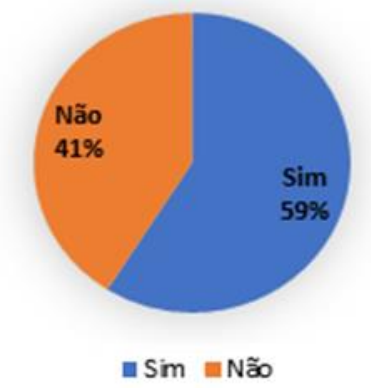

Fonte: Própria (2021).

Analisando o gráfico, entende-se que 59\% dos estudantes afirmaram que já possuíam conhecimento sobre o assunto, contudo, $41 \%$ mostraram nunca ter ouvido falar sobre os aspectos químicos envolvidos por trás das fotografias, o que é algo preocupante para a matriz curricular, visto que é de fundamental importância que os educadores sejam detentores de conhecimentos que superem aqueles exigidos nas ementas dos Cursos de Licenciatura (ROSÁRIO et al., 2019). 
Ainda concernente aos dados do Gráfico 01, foi possível notar que as porcentagens apresentaram valores próximos, manifestando a necessidade do aumento nos debates a respeito do tema. Muitas pesquisas apontam que um dos principais motivos causadores do desinteresse dos discentes em estudos voltados para a disciplina de Química, é a abordagem do professor em sala de aula, que na maioria dos casos, é tradicionalista e metódica. Assim, docentes em formação necessitam de uma capacitação acadêmica adequada, vislumbrando métodos de ensino atuais e inovadores em sala de aula, objetivando a superação dos impasses costumeiros no processo de ensino e aprendizagem.

No IFA também houve a evocação livre de palavras e o questionamento foi: "Depois da sua participação na palestra, responda mais uma vez o que vem a sua mente quando você escuta o termo "Fotografia". Para responder cite 5 (cinco) palavras que você rapidamente associa a esse termo." Os resultados obtidos neste último instrumento avaliativo apresentaram uma significativa diferença quando comparados aos do ISA, uma vez que boa parte das respostas foram constituídas por termos técnicos e científicos próprios da disciplina de Química. Os dados relatados estão descritos no Quadro 04.

\begin{tabular}{|c|l|} 
Quadro 04: Palavras associadas à Fotografia no IFA. \\
\begin{tabular}{|c|l|}
\hline Pesquisados & \multicolumn{1}{|c|}{ IFA } \\
\hline Aluno A & Química; NOX; Reações químicas; Processos e Ácido/base. \\
\hline Aluno B & Química; Contextualização; Conteúdos. \\
\hline Aluno C & Câmera; Luz; Fótons; Pixel e Química. \\
\hline Aluno D & Reações; Luz; Metais; Câmeras; Papel. \\
\hline Aluno E & Química; Reações; Revelação; Componentes de luz; Óxido-redução. \\
\hline Aluno F & Espectroscopia; Fótons; Reação química; Processo de revelação. \\
\hline Aluno G & Reações; Fotos; Química; Oxirredução; Tipos de câmeras. \\
\hline Aluno H & Quarto escuro; Imagens; Reação de oxirredução; Energia; Fóton. \\
\hline
\end{tabular}
\end{tabular}

Fonte: Própria (2021).

As palavras resultantes das evocações livres, foram consideravelmente diferentes das primeiras associações feitas pelos discentes, isso indicou que após o momento de discussão e fundamentação da temática, os mesmos obtiveram uma nova concepção a respeito do assunto. Esse fator evidencia a valia na utilização da contextualização no ensino de Química tanto na graduação, quanto na sua finalidade na prática docente em turmas de Ensino Médio. Todas essas interpretações dos resultados se justificam ao passo de que o ato de contextualizar, sucede na aproximação do conteúdo formal (científico) com do conhecimento trazido pelos educandos (não formal), tornando os conteúdos escolares interessantes para eles (KATO; KAWASAKI, 2011).

Em sequência, o mesmo instrumento possuiu como outro questionamento a pergunta: 


\section{CICLO DE PALESTRAS}

"O que você achou da palestra intitulada: "Revelando a Química: o estudo das ciências nas fotografias"?. Dentre as respostas analisadas, pode-se destacar uma que relatou inteiramente todas as discussões realizadas até o momento, a resposta foi a seguinte: Aluno A: "Acho de suma importância, introduzir assuntos do dia a dia, ou seja trazer a química através da fotografia é algo de suma relevância". O dado apresentado se confirma no pensamento de Marques (2012), que enxerga a "fotografia" como fator recorrente na rotina da população, possibilitando a usabilidade do tema, quando se deseja trabalhar interdisciplinarmente com as Ciências, objetivando um ensino mais fundamentado para os alunos.

Ainda a respeito da referida questão, houveram algumas outras observações significativas, sendo essas: Aluno B. "Conhecia o tema, mas não da maneira que foi abordada, pois eu não conhecia a química que ocorria nesse processo. Foi muito interessante e pode servir inclusive para que a gente use como exemplo de contextualização nas nossas aulas sobre oxirredução ou reações químicas."; Aluno C. "É de suma importância relatar os detalhes que acontecem na fotografia, visto que se tem a presença de sais, ions, fótons etc., pois é um assunto bastante presente em nosso cotidiano e consequentemente pode ser abordado no conteúdo específico de química, como Oxirredução, ions ou sais. ”. Deste modo, a atividade de ensino pode ser considerada como uma ação fundamental para a formação docente do público pesquisado.

\section{CONCLUSÕES}

Em virtude dos resultados provenientes das palestras sobre "Fotografia" e "Alquimia", foi possível identificar a grande importância de atividades de ensino com temas não habituais para discentes de Cursos de Licenciatura em Química. Uma vez que essas conversações metodológicas motivam os graduandos a melhorar seus entendimentos em diversas áreas da ciência, promovendo avanços consideráveis no conhecimento cognitivista dos mesmos.

Portanto, as interações dos participantes na atividade evidenciaram a eficiência da aplicabilidade do "Ciclo de Palestras" para o processo de ensino e aprendizagem, corroborando na formação acadêmica dos discentes presentes, por intermédio do enriquecimento de seus currículos acadêmicos.

Por fim, é indispensável ressaltar que a presente pesquisa contribui como uma proposta para que as barreiras de ensino estabelecidas entre os discentes e os conteúdos das Ciências da Natureza, sejam superadas e, em decorrência disso, os estudantes, tanto do nível médio, como de graduação, obtenham uma nova e melhorada concepção da Química. 


\section{REFERÊNCIAS}

ALBUQUERQUE, Anaquel Gonçalves. A importância da contextualização na prática pedagógica. Research, Society and Development, v. 8, n. 11, p. e488111472-e488111472, 2019. Disponível em: http://dx.doi.org/10.33448/rsd-v8i11.1472. Acesso em: 26 ago 2021.

ANTUNES, Jeferson et al. Diagnóstico rápido participativo como método de pesquisa em educação. Avaliação: Revista da Avaliação da Educação Superior (Campinas), v. 23, n. 3, p. 590-610, 2018. Disponível em: https://doi.org/10.1590/S1414-40772018000300002. Acesso em: 26 ago 2021.

BRASIL. Lei n ${ }^{\circ}$ 9.394, 20 de dezembro de 1996. Lei de Diretrizes e Bases da Educação Nacional. Diário Oficial da República Federativa do Brasil, Brasília, DF, 21 dez. 1997. Disponível em: http://www.planalto.gov.br/ccivil_03/leis/19394.htm. Acesso em: 25 ago. 2021.

BRASIL. PCN + Ensino Médio: orientações educacionais complementares aos Parâmetros Curriculares Nacionais - Ciências da Natureza, Matemática e suas Tecnologias. Brasília, DF: MEC/SEMTEC, $2002 . \quad$ Disponível em: http://portal.mec.gov.br/seb/arquivos/pdf/CienciasNatureza.pdf. Acesso em: 26 ago 2021.

CAVALCANTE, Beatriz Pereira; TEIXEIRA, Aline Maria dos Santos; MARCELO, Luciana Resende. O desastre de Mariana como abordagem investigativa e CTSA no ensino de química. Revista de Educação, Ciências e Matemática, v. 9, n. 2, 2019. Disponível em: http://publicacoes.unigranrio.edu.br/index.php/recm/article/view/4729. Acesso em: 25 ago. 2021.

COSTA, Jaqueline de Morais; PINHEIRO, Nilcéia Aparecida Maciel. O ensino por meio de temas-geradores: a educação pensada de forma contextualizada, problematizada e interdisciplinar. Imagens da Educação, v. 3, n. 2, p. 37-44, 2013. Disponível em: https://periodicos.uem.br/ojs/index.php/ImagensEduc/article/view/20265. Acesso em: 25 ago. 2021.

FERREIRA, Márcio Diogo Rodrigues. Das origens da alquimia, até o surgimento da química. 2012. vi, 29 f. Monografia (Licenciatura em Química) - Universidade de Brasília, Brasília, 2012. Disponível em: https://bdm.unb.br/handle/10483/4870 . Acesso em: 27 ago. 2021.

FINGER, Isadora; BEDIN, Everton. A contextualização e seus impactos nos processos de ensino e aprendizagem da ciência química. Revista Brasileira de Ensino de Ciências e Matemática, v. 2, n. 1, p. 8-24, 2019. Disponível em: http://seer.upf.br/index.php/rbecm/article/view/9732. Acesso em: 25 ago. 2021.

FREIRE, P. Pedagogia do oprimido. 11. ed. Rio de Janeiro: Paz e Terra, 1982.

FREIRE, P. Pedagogia do oprimido. 17. ed. Rio de Janeiro: Paz e Terra, v.3,1987.

GOMES, Alex de Oliveira; COSTA, Jerônimo da Silva. Utilização do histórico de descoberta de fármacos como estratégia para contextualização no ensino de química. Revista Eletrônica Perspectivas da Ciência e Tecnologia-ISSN: 1984-5693, v. 9, n. Único, p. 62-79, 2017. Disponível em: https://revistascientificas.ifrj.edu.br/revista/index.php/revistapct/article/view/797. Acesso em: 
25 ago. 2021.

KATO, Danilo Seithi; KAWASAKI, Clarice Sumi. As concepções de contextualização do ensino em documentos curriculares oficiais e de professores de ciências. Ciência \& Educação (Bauru), v. 17, p. 35-50, 2011. Disponível em: https://doi.org/10.1590/S151673132011000100003. Acesso em: 28 ago 2021.

LIMA, Fernanda Oliveira; CUNHA, Marcia Borin da. A fotografia como recurso didático para contextualizar conceitos de Química Analítica. Research, Society and Development, v. $9, \quad$ n. $\quad 3, \quad$ p. $\quad 19, \quad 2020 . \quad$ Disponível em: https://dialnet.unirioja.es/servlet/articulo?codigo=7340967. Acesso em: 26 ago. 2021.

LIMA, Telma Cristiane Sasso de; MIOTO, Regina Célia Tamaso. Procedimentos metodológicos na construção do conhecimento científico: a pesquisa bibliográfica. Revista Katálysis, v. 10, n. SPE, p. 37-45, 2007. Disponível em: https://doi.org/10.1590/S141449802007000300004. Acesso em: 26 ago 2021.

LOBO, Renato Fernandes. O uso da Cultura Pop nas aulas de História. Revista Discente Ofícios de Clio, v. 4, n. 6, p. 103, 2019. Disponível em: https://DOI.ORG/10.15210/CLIO.V4I6.14134. Acesso em: 25 ago 2021.

MARQUES, Fernanda do Nascimento. A química da fotografia na perspectiva CTS de ensino. 2012. Disponível em: https://bdm.unb.br/handle/10483/4071. Acesso em: 27 ago 2021.

MARTINS, Macaulay Ferreira et al. A fotografia como proposta interdisciplinar no ensino de ciências. 2017. Disponível em: http://dspace.sti.ufcg.edu.br:8080/jspui/handle/riufcg/7405. Acesso em: 26 ago. 2021.

MARQUES, Marieli. O uso de diferentes estratégias em aulas de Química para o Ensino Superior. Revista Internacional de Educação Superior, v. 7, 2021. Disponível em: https://doi.org/10.20396/riesup.v7i0.8659572. Acesso em: 27 ago 2021.

MELO, Ana Paula; ROCHA, Dalva Cassie. Reflexões sobre a importância da História e Filosofia da Ciência no Ensino de Ciências. Revista Espaço Acadêmico, v. 17, n. 192, p. 6977, 2017.2 Disponível em: https://periodicos.uem.br/ojs/index.php/EspacoAcademico/article/view/33078. Acesso em: 26 ago 2021.

MIRANDA, Ana Carolina Gomes; PAZINATO, Maurícius Selvero; BRAIBANTE, Mara Elisa Fortes. Temas geradores através de uma abordagem temática freireana: contribuições para o ensino de ciências. Revista de Educação, Ciências e Matemática, v. 7, n. 3, 2017. Disponível em: http://publicacoes.unigranrio.edu.br/index.php/recm/article/view/4060. Acesso em: 25 ago. 2021.

MÓL, Gerson de Souza. Pesquisa qualitativa em ensino de química. Revista Pesquisa Qualitativa, v. 5, n. 9, p. 495-513, 2017. Disponível em: https://editora.sepq.org.br/rpq/article/view/140/96. Acesso em: 26 ago 2021. 
NASCIMENTO, Hemerson Henrique Ferreira; SIMÕES NETO, José Euzébio. Emergências da Alquimia na Cultura Moderna: a Arte na Literatura, Cinema e Televisão. XVI ENEQ/X EDUQUI-ISSN: $2179-5355, \quad 2012.24$ Disponível https://periodicos.ufba.br/index.php/anaiseneq2012/article/view/7541. Acesso em: 24 ago 2021.

NEVES, Dulce Amélia B. et al. Protocolo verbal e teste de associação livre de palavras: perspectivas de instrumentos de pesquisa introspectiva e projetiva na ciência da informação.

Ponto de Acesso, v. 8, n. 3, p. 64-79, 2014. Disponível em: https://periodicos.ufba.br/index.php/revistaici/article/view/12917/9240. Acesso em: 25 ago 2021.

OLIVEIRA, Luigi Lisboa. Cultura POP: quadrinhos, cinema e super-heróis na construção do ensino de ciências e biologia. Revista UNIANDRADE, v. 22, n. 1, p. 22-37, 2021. Disponível em: https://revista.uniandrade.br/index.php/revistauniandrade/article/view/1873/1371. . Acesso em: 25 de ago. De 2021.

RAUPP, Fabiano Maury; BEUREN, Ilse Maria. Metodologia da pesquisa aplicável às ciências. Como elaborar trabalhos monográficos em contabilidade: teoria e prática. São Paulo: Atlas, p. 76-97, 2006. Disponível em: https://shortest.link/JR8. Acesso em: 25 ago 2021.

ROCHA, Guilherme Sales da; LEAL, Wesley de Souza; MESSEDER, Jorge Cardoso. O uso da fotografia no estudo da tabela periódica. Revista Dynamis, v. 25, n. 2, p. 205-223, 2019.Disponível em: https://proxy.furb.br/ojs/index.php/dynamis/article/view/8041/4362. Acesso em: 26 ago. 2021.

ROSÁRIO, Lucas Oliveira; FERREIRA, José Leonardo Alves; SANTOS, Rhayane de Oliveira; RODRIGUES, Kamilla Karoline Pereira; FIGUEIRÊDO, Alessandra Marcone Tavares Alves de. Proposta de ensino interdisciplinar: abordagem de temáticas diversificadas no curso de licenciatura em química do IFPB, campus João Pessoa. Anais VI Cointer PDVL, v.1, p. 0-18, 2011. Disponível em: https://doi.org/10.31692/23589728.VICOINTERPDVL.2019.0134. Acesso em: 25 ago 2021.

SANTOS, Jefferson Rodrigo; FERREIRA, Maria Elisa. Um relato de ensino de Química no contexto da pandemia de COVID-19 na rede pública de São Paulo: O desafio das aulas virtuais na Educação Básica. Research, Society and Development, v. 10, n. 2, p. e8710212267-e8710212267, 2021. Disponível em: http://dx.doi.org/10.33448/rsdv10i2.12267. Acesso em: 23 ago 2021.

SANTOS, F. R. dos; AMARAL, C. L. C. Forensic chemistry as a contextualizing theme in the teaching of chemistry. Research, Society and Development, [S. l.], v. 9, n. 3, p. e198932772, 2020. DOI: 10.33448/rsd-v9i3.2772. Disponível em: https://rsdjournal.org/index.php/rsd/article/view/2772. Acesso em: 25 ago. 2021.

SANTOS, Mariangela Bruch dos, et al. Colesterol: Uma temática para contextualizar o ensino de Química. Brazilian Journal of Development, v. 6, n. 11, p. 88810-88823, 2020. Disponível em: https://www.brazilianjournals.com/index.php/BRJD/article/view/19982. Acesso em: 25 ago. 2021. 


\section{CICLO DE PALESTRAS}

SANTOS, Thaís Sanches; CRISTINA, Nathália; CARVALHO, Helder Silva. "Animais fantásticos e onde habitam": utilizando a cultura-POP no ensino de zoologia. Arquivos do Mudi, v. 24, n. 2, p. 78-83, 2020. Disponível em: https://periodicos.uem.br/ojs/index.php/ArqMudi/article/view/54644. Acesso em: 25 de ago. de 2021. 